\title{
Knowledge and Barriers of Critical Care Nurses Regarding Evidence-Based Practices in Ventilator-Associated Pneumonia Prevention
}

\author{
Moath Naif Alkhazali (D), Nurhan Bayraktar (D), Khalid Anwer Al-Mugheed (D) \\ Department of Surgical Nursing, Near East University Faculty of Nursing, Nicosia, North Cyprus
}

ORCID iDs of the authors: M.N.A. 0000-0003-4242-9262; N.B. 0000-0002-3072-5788; K.A.Al-Mugheed 0000-0002-5227-3954

Cite this article as: Alkhazali MN, Bayraktar N, Al-Mugheed KA. Knowledge and barriers of critical care nurses regarding evidencebased practices in ventilator-associated pneumonia prevention. Cyprus J Med Sci. 2021; 6(3): 185-191.

BACKGROUND/AIMS

To investigate the knowledge among nurses who work in critical care units on the prevention of ventilator-associated pneumonia (VAP) and their barriers of adherence to preventive measures.

\section{MATERIAL and METHODS}

The study was performed using descriptive cross-sectional design in two hospitals in Jordan, which included 185 critical care nurses. The data were collected between June-July 2017. The questionnaire was covered 30 questions related to knowledge of VAP prevention as well as eight statements about barriers of adherence to VAP prevention guidelines. Data were evaluated using descriptive statistics, Kruskal-Wallis test, and Mann-Whitney U tests.

\section{RESULTS}

The findings of the present study revealed that nurses' overall mean of knowledge on VAP prevention were adequate level (19.6 \pm 3.43 out of 30) with low-level knowledge regarding prevention strategies of VAP. Lack of equipment's (65.9\%), forgetting to practice the sterile techniques (54.1\%), and lack of time to deliver proper infection control (53.0\%) were the main barriers mentioned by Jordanian critical care nurses of VAP prevention. Nurse's with high experience and master degree showed significantly better knowledge of VAP prevention than their other groups.

\section{CONCLUSION}

Achieving an adequate knowledge of VAP prevention is an important feature for reinforcing patient care outcomes. The results of this study highlighted to necessity of creating new strategies for improving knowledge of critical care nurses and removing their barriers regarding VAP prevention.

Keywords: Critical care nurses, intensive care unit, ventilator associated pneumonia, ventilator bundle

\section{INTRODUCTION}

Ventilator-associated pneumonia (VAP) is the most serious acquired infections in intensive care units (ICUs) for patients undergoing mechanical ventilation.' The infection can progress after intubation between 48 or 72 hours. In some cases, it may be related to healthcare providers. ${ }^{2} \mathrm{VAP}$ is considered the most significant cause of death in ICU. ${ }^{3,4}$ Lately, it is estimated that between $9-13 \%$ deaths were as a result of ventilator assistance devices. ${ }^{5} \mathrm{VAP}$ accounts for $25 \%$ of all types of ICUs acquired infections. ${ }^{6}$ Consequently it leads to prolonged hospitalization and ICUs stay. Moreover, it contributes to increased length of mechanical ventilation, which increases the cost of treatment to approximately $\$ 40,000$ per patient. $^{8}$

In developing countries, multiple studies indicated a significant increase in VAP incidence. In northern India, the incidence of 40.I VAP infections/1,000 ventilator days. In Costa Rica, the incidence of 44.3 VAP infections/I,000 ventilator days. ${ }^{10}$ In another study, In Iran, is $21.6 \%$ or 9.96 per I,000 days of ventilation." Multiple factors contribute to the increasing rate of VAP such as tracheostomy, reintubation, impaired consciousness, and presence of an endotracheal tube. ${ }^{2}$ There is a few accurate information on VAP prevalence in Jordan hospitals, nevertheless a study found a prevalence rate of 
29 cases per 1,000 ventilator-days and a mortality rate of $53 \%$ related to $\vee A$ P. $^{13}$ A few studies have been performed among Jordanian critical care nurses to assess their compliance and knowledge of VAP, yet, still not effectively and questionable. For instance, in a two-group post-test design study among critical care nurses, they demonstrated moderate compliance. ${ }^{14}$ In pre- and post-intervention study majority of nurses revealed low knowledge level regarding VAP preventative measures, risk factors and pathophysiology. ${ }^{15}$ An observational study, after 5 months of observations, revealed more than half of nurses had "insufficient compliance." "I6 In another study, Aloush et al., survey was performed for three countries: Jordan, Saudi Arabia, Egypt, the study showed insufficient compliance for both nurses and hospitals. ${ }^{17}$ That leads to adverse outcomes, and impact the quality of care.

There were many barriers in Jordan that impede nurses with respect to $V A P$ prevention practices, the most common ones are; lack of equipment, low level of compliance with infectioncontrol standards, 18 lack of time and work load, ${ }^{15}$ lack of education, resources, and experience. ${ }^{17}$ Hence, it is susceptible to increasing $\mathrm{VAP}$ incidence.

In critical care units, VAP prevention is prioritized for intubated patients. ${ }^{19}$ Many organizations such as the European Respiratory Society, The Society for Healthcare Epidemiology of America $^{3}$ has launched a concept "ventilator bundle" to decrease VAP mortality and enhance prevention, it comprises several clinical practice guidelines. These guidelines combinations such as oropharyngeal hygiene, suction endotracheal secretions, ${ }^{3}$ the elevation of the head at $30-45^{\circ}$ and facilitating early mobilization. ${ }^{20}$ Even though considered as low-costs and nonpharmacological practices as well as efficient for preventing $V A P$, yet still Jordanian critical care nurses showed insufficient capacity. ${ }^{21}$ Substantial evidence shows that the implementation of a VAP prevention bundle is a proven way in respect to providing an efficacious reduction in VAP rates, ${ }^{22}$ improving patient safety, and enhancing the quality of care. ${ }^{23}$

Determination the knowledge among critical care nurses related to $\mathrm{VAP}$ prevention, and the barriers to the obligation to implement evidence preventives may be useful in improving their awareness, thus leading to better practices and preventing this important problem in Jordan. Thus, this study aims to investigate the knowledge of VAP prevention guidelines and determine the barriers which impede to the obligation of preventive strategies among critical care nurses. In this context, the research questions were:

- What is the knowledge level of critical care nurses on the prevention of $\vee A P$ ?

- What are the barriers which may prevent critical care nurses to adhere to preventive measures of $V A P$ ?

- Is there any difference between descriptive characteristics and knowledge of the nurses working in critical care units on the prevention of $\vee A P$ ?

\section{MATERIAL and METHODS Study Design}

The study was designed in a descriptive cross-sectional. It was conducted at two randomly hospitals in the middle and northern region in Jordan. The King Abdullah University Hospital is an affiliated hospital to the largest and leading university of Jordan which is located in the northern part of Jordan. The hospital consists of 15 floors and 683 beds, 12 operating theaters, 78-intensive care beds for adult and child patients. It has care bundles for VAP prevention. The Islamic hospital located in the middle part of Jordan, it has a capacity of 300 beds, eight operating theaters and 25 intensive care beds and hospital protocol for prevention of VAP.

\section{Study Population}

The study population was composed of 193 registered nurses who were working at day or night shift in ICU departments of the hospitals. A total of 132 nurses were working in the ICU units in the first hospital and $6 \mathrm{I}$ nurses in ICU in second hospital. Nurses work in the ICUs with at least one year experience, willing to participate and hold a bachelor's degree were involved in the study. Nurses who have a diploma degree in nursing and trainees were out of the study.

\section{Study Instrument}

A questionnaire which was used as a data collection tool in this study by the researchers was based on recent evidencebased guidelines of VAP prevention., ${ }^{1,3}$ The questionnaire composed of three sections. The first section with eight questions included the demographic characteristics of the nurses. The second section had questions regarding the knowledge needed in the prevention of $V A P$, which had 30 questions with two options; true option was marked I, false option was 0, questionnaire contains eight items negative statements (items $4,7,9,11,17,19,20$, and 23) were recorded to compute a percent correct statements response rate. The last section consisted of eight questions with three response options of "Always/ Sometimes/Never" designed to determine the barriers to adherence to $\mathrm{VAP}$ prevention measures.

In the current study, Cronbach's $\alpha$ was showed an acceptable range of 0.77 . Questionnaire content was assessed for clarity and acceptability by three ICU nurse specialists and necessary revisions were made based on their recommendations. Then, a pilot study was implemented in 10 nurses, since there was not reported any difficulty and obscurity in questionnaire content, these nurses were included in the main sample. Researchers were using the English language for survey content because it is the official language for teaching at all of the nursing faculties in Jordan.

\section{Data Collection}

Data were collected in a period from 20 June to July 20, 2017 by using self-completion method filled out the study questionnaire. Before collecting data, researchers sent an official letter from the principal investigator, along with hospital director permission to nurse manager of ICUs in both hospitals to encourage critical care nurses to participate in this study, as well as informing them the results will not affect your annual evaluation. After encouragement and explanation the purpose of the study we distributed the questionnaires depending on the hospital size, each participant received a copy of the informed consent and questionnaire. During data collection, researchers avoided the period's nurses were providing treatment and care to patients, to avoid stressing participants that could affect the proficiency of the data collection process. Duration of questionnaire between 10 to 15 minutes, after completion, researchers collected it immediately to obviate data miss, also we informed 
them you can keep it with you and give back to researchers, inside the sealed envelope without using any employee information's to ensure privacy. Ethical approval was secured from the Near East University Institutional Reviews Board (IRB) and permission was obtained from the director of the hospitals. Written informed consent was sought from all participants.

\section{Statistical Analysis}

All survey papers were kept in a closed locker in investigator office, as well as data were inserted to the Statistical Package for the Social Sciences, version 22.0 (IBM SPSS Corp.; Armonk, NY, USA) using numeric codes and saved on password computer. Descriptive statistic included frequency and percentages were performed to describe characteristics of the nurses, knowledge prevention and barriers of VAP. The highest score of knowledge prevention was 30 and the lowest 0 . Mean knowledge prevention $(\geq 15)$ were reflected as inadequate knowledge; while score more than $(>15)$ were indicated adequate knowledge. A nonparametric tests Kruskal-Wallis test and Mann-Whitney $U$ test was used to compare knowledge in prevention concerning demographic characteristics. $P<.05$ sets a significance.

\section{RESULTS}

Once completed, 185 out of 193 completed the questionnaire with a response rate of $95.9 \%$, eight of them did not fill the questionnaire. The mean age of the participants was the 26-30 age group $(55.1 \%)$. Females composed the majority of the participants $(58.4 \%)$. Most of the participants had bachelor's degrees (89.2\%). The majority of the nurses had an experience of fewer than 5 years as registered nurses (60.1\%).

The majority of the nurses had already received VAP education (7I.4\%). The participants mentioned educational resources where they had received the related education, with external courses making up $24.9 \%$, the highest rate in this respect. As far as the quality of VAP education was concerned, most of the nurses $(86.9 \%)$ held the opinion that the education was "Satisfactory." The majority of the nurses mentioned that they wanted to be educated on VAP (79.5\%) (Table I).

Concerning the knowledge of evidence-based guidelines of $\checkmark A P$ prevention, they had an adequate overall mean knowledge, with $(19.6 \pm 3.43)$. The results of the study showed that the highest correct response rates were delivered in terms of; elevating the head of the bed to $30-45^{\circ}(89.2 \%)$, regular oral care with chlorhexidine (88.7\%), followed by adequate hand hygiene (88.6\%), continual education for ICU nurses (88.1\%), proper sterilization and disinfection of respiratory care equipment $(87.6 \%)$, VAP is the cause of highest mortality among nosocomial infections $(86.5 \%)$, and assess readiness of the patient to extubate daily ( $84.9 \%$ ) (Table 2 ).

Table 3 shows the barriers the nurses have to face in respect of adherence to VAP prevention guidelines. Findings revealed that most of the nurses responded in the option of "sometimes" with respect to the barriers nurses face regarding adherence to VAP prevention guideline. The option of "Shortage of staff in the ICU" got most of the answers. In "always" option (51.4\%) and "Lack of VAP Prevention Knowledge" (49.7\%). As far as the answers in the option of "sometimes" are concerned, it was the items of "Lack of equipment such as gloves and face masks" (65.9\%), "Hospital system insufficiencies" (54.1\%), and "Lack of time to deliver proper infection control" (53.0\%).

\begin{tabular}{|c|c|c|}
\hline Demographic characteristics & $N$ & $\%$ \\
\hline \multicolumn{3}{|l|}{ Age (mean :28.I) } \\
\hline$\leq 25$ years & 44 & 23.8 \\
\hline $26-30$ years & 102 & 55.1 \\
\hline$\geq 31$ & 39 & 21.1 \\
\hline \multicolumn{3}{|l|}{ Gender } \\
\hline Male & 77 & 41.6 \\
\hline Female & 108 & 58.4 \\
\hline \multicolumn{3}{|l|}{ Education degree } \\
\hline Bachelor's & 165 & 89.2 \\
\hline Master degree & 20 & 10.8 \\
\hline \multicolumn{3}{|l|}{ Working experience in the ICU } \\
\hline$\leq 5$ years & $\| 4$ & 61.6 \\
\hline $6-10$ years & 62 & 33.5 \\
\hline$\geq$ Il years & 9 & 4.9 \\
\hline \multicolumn{3}{|l|}{ Previous VAP education } \\
\hline Yes & 132 & 71.4 \\
\hline No & 53 & 28.6 \\
\hline \multicolumn{3}{|l|}{ Education resource $(N=132)^{*}$} \\
\hline Nursing school & 20 & 10.8 \\
\hline External courses & 46 & 24.9 \\
\hline Web resources & 17 & 9.2 \\
\hline In-service education & 32 & 17.3 \\
\hline Other & 13 & 7.0 \\
\hline \multicolumn{3}{|c|}{ Quality of the VAP education $(N=132)^{*}$} \\
\hline Satisfied & $\| 4$ & 86.9 \\
\hline Dissatisfied & 18 & |3.1 \\
\hline \multicolumn{3}{|l|}{ Need for education on VAP } \\
\hline Yes & 147 & 79.5 \\
\hline No & 38 & 20.5 \\
\hline
\end{tabular}

Regarding the correlation between nurses' age, years of ICU experience and previous VAP education with knowledge of evidence-based guidelines of $V A P$ prevention revealed no statically significant differences. The study revealed that nurses with $\leq 25$ years old had higher $V A P$ prevention knowledge mean rates $(19.7 \pm 3.2)$ than other age groups. The nurses who had $\geq$ ll years of experience showed higher mean rates $(20.6 \pm$ 3.6) on VAP prevention knowledge than the groups with 6-10 and $\leq 5$ years. The nurses who had previous $V A P$ education had high mean prevention knowledge $(19.8 \pm 3.3)$ than nurses without $V A P$ education (Table 4).

\section{DISCUSSION}

The main focus of the present study was to determine knowledge of critical care nurses toward VAP prevention guidelines and the barriers which they face in respect of adherence to preventive measures in critical care units. In the current study, the mean overall knowledge of VAP prevention was adequate, contrary to previous studies which reported mean scores knowledge were relatively low. ${ }^{24-26}$ The explanations of higher mean scores might be related to the participant's effective memory since most of them were fresh graduates, which could easily remember what they had learned. Another explanation may be attributed to the revising and correcting which was made to create a new questionnaire on knowledge regarding VAP prevention. In the current study, our participants had highest correct answers about elevating the head of the bed to 30$45^{\circ}$, regular oral care with chlorhexidine, adequate hand 
TABLE 2. Nurses' General Knowledge of VAP Prevention $(\mathrm{N}=185)$

\begin{tabular}{|c|c|c|c|}
\hline \multirow[b]{2}{*}{ Statements on VAP } & \multirow[b]{2}{*}{$\mathrm{T} \backslash \mathrm{F}$} & \multicolumn{2}{|c|}{ Correct answer } \\
\hline & & $\mathbf{N}$ & $\%$ \\
\hline The ventilator associated pneumonia (VAP) is pneumonia that occurs $>$ or equal 48 hours after endotracheal intubation & $\mathrm{T}$ & $|5|$ & 81.6 \\
\hline VAP is the most prevalent infection in intensive care units & $\mathrm{T}$ & 140 & 75.7 \\
\hline Automated control of endotracheal tube cuff pressure is important because it decreases the risk for VAP & $\mathrm{T}$ & 102 & 55.1 \\
\hline Over feeding a ventilated patient is associated with increased the risk for VAP & $\mathrm{T}$ & 144 & 77.8 \\
\hline Whenever feasible, noninvasive positive pressure ventilation should be used to prevent $V A P$ & $\mathrm{~T}$ & 98 & 53.0 \\
\hline It is necessary to manage patients without sedation whenever possible to prevent VAP & $\mathrm{T}$ & $\| 3$ & 61.1 \\
\hline Benzodiazepines should always be preferred to manage agitation & $\mathrm{F}$ & 107 & 57.8 \\
\hline Sedation should be interrupted daily to prevent $V A P$ & $\mathrm{~T}$ & 119 & 64.3 \\
\hline It is necessary to assess readiness to extubate of the patient daily to prevent VAP & $\mathrm{T}$ & 157 & 84.9 \\
\hline Pairing spontaneous breathing trials with spontaneous awakening trials is not necessary & $\mathrm{F}$ & 123 & 66.5 \\
\hline Proper sterilization and disinfection of respiratory care equipment is important to prevent VAP & $\mathrm{T}$ & 162 & 87.6 \\
\hline Oral route is recommended for endotracheal intubation to prevent $V A P$ & $\mathrm{~T}$ & 118 & 63.8 \\
\hline Prophylactic probiotics may be useful to prevent VAP & $\mathrm{T}$ & 134 & 72.4 \\
\hline Ultrathin polyurethane endotracheal tube cuffs may lower VAP rates & $\mathrm{T}$ & 68 & 36.8 \\
\hline Saline instillation before tracheal suctioning may cause to VAP & $\mathrm{F}$ & 70 & 37.8 \\
\hline Mechanical tooth brushing may be useful in prevention of VAP & $\mathrm{T}$ & 109 & 58.9 \\
\hline Closed/in-line endotracheal suctioning reduce the risk of VAP & $\mathrm{F}$ & 48 & 25.9 \\
\hline Kinetic beds reduce the risk of $\mathrm{VAP}$ and recommended & $\mathrm{F}$ & 63 & 34.1 \\
\hline Adequate hand hygiene between patients and change gloves is important to prevent the VAP & $\mathrm{T}$ & 164 & 88.6 \\
\hline Prone positioning intermittently may prevent $\mathrm{VAP}$ and recommended & $\mathrm{F}$ & 105 & 56.8 \\
\hline Using selective oral or digestive decontamination to reduce risk $V A P$ & $\mathrm{~T}$ & 129 & 69.7 \\
\hline Care bundles may be useful in reducing VAP & $\mathrm{T}$ & 149 & 80.5 \\
\hline
\end{tabular}

TABLE 3. Barriers of Nurses to Adherence to VAP Prevention Guidelines ( $N=185$ )

\begin{tabular}{|c|c|c|c|c|c|c|}
\hline \multirow[b]{2}{*}{ Statements about barriers } & \multicolumn{2}{|c|}{ Always } & \multicolumn{2}{|c|}{ Sometimes } & \multicolumn{2}{|c|}{ Never } \\
\hline & $\mathbf{N}$ & $\%$ & $\mathrm{~N}$ & $\%$ & $\mathbf{N}$ & $\%$ \\
\hline Lack of $\bigvee A P$ prevention knowledge & 92 & 49.7 & 76 & 41.1 & 17 & 9.2 \\
\hline Shortage of staff in the ICU & 95 & 51.4 & 70 & 37.8 & 20 & 10.8 \\
\hline Lack of equipment such as gloves and face masks & 40 & 21.6 & 122 & 65.9 & 23 & 12.4 \\
\hline Lack of written VAP protocol at the hospital & 72 & 38.9 & 89 & 48.1 & 24 & 13.0 \\
\hline Hospital system insufficiencies & 76 & 41.1 & 90 & 48.6 & 19 & 10.3 \\
\hline Forgetting to practice the sterile technique & 68 & 36.8 & 100 & 54.1 & 17 & 9.2 \\
\hline
\end{tabular}

hygiene, continual education for ICU nurses proper sterilization and disinfection of equipment, assessing the readiness of the patient for intubation and importance of care bundles. There is evidence in the relevant literature about these preventive measures. A study found that head-of-bed elevation to $30-45^{\circ}$ significantly decreases the prevalence of VAP. ${ }^{27}$ A recent study shows that Jordanian nurses were using, more than Saudi Arabia and Egypt nurses, chlorhexidine solution. ${ }^{17}$ Another study held among Jordanian nurses that showed around twothird of them wash their hands before and after performing patient care. ${ }^{18}$ It also revealed significant improvement among nurses after VAP training. ${ }^{23}$ A review study concluded the asepsis is the main mode of mechanical ventilation pneumonia prevention. ${ }^{28}$ A study found a substantial decreasing of incidence and risk of VAP after implementation of the ventilator care bundle. ${ }^{29}$

Although the high level of correct answers in respect of several strategies, results revealed the participants had a low level of correct knowledge regarding interventions which are considered as high and moderate interventions like; noninvasive positive pressure ventilation, minimizing pooling of secretions above the endotracheal tube cuff, oral route, noninvasive positive pressure, selective oral or digestive decontamination, and patients without sedation with studies. ${ }^{15,30,3 \mid}$ These findings are attributed to several reasons; shortage of staff and resources, ${ }^{15}$ 
TABLE 4. Relationship between Knowledge of VAP Prevention and Demographic Characteristics of the Nurses

\begin{tabular}{|c|c|c|c|}
\hline $\begin{array}{l}\text { Demographic } \\
\text { characteristics }\end{array}$ & $\begin{array}{l}\text { VAP knowledge } \\
\text { prevention mean }\end{array}$ & & SD \\
\hline \multicolumn{4}{|l|}{ Age } \\
\hline$\leq 25$ years & 19.3 & & 3.4 \\
\hline $26-30$ years & 19.7 & & 3.2 \\
\hline$\geq 31$ years & 19.4 & & 4.0 \\
\hline $\bar{P}$ & & 744 & \\
\hline \multicolumn{4}{|l|}{ ICU experience } \\
\hline$\leq 5$ years & 19.5 & & 3.4 \\
\hline $6-10$ years & 20.4 & & 3.2 \\
\hline$\geq 11$ years & 20.6 & & 3.6 \\
\hline$P$ & & 249 & \\
\hline \multicolumn{4}{|l|}{ Education degree } \\
\hline Bachelor's & 19.4 & & 3.3 \\
\hline Master degree & 20.6 & & 3.8 \\
\hline$P$ & & .161 & \\
\hline \multicolumn{4}{|c|}{ Previous VAP education } \\
\hline Yes & 19.8 & & 3.3 \\
\hline No & 19.0 & & 3.5 \\
\hline$P$ & & .160 & \\
\hline
\end{tabular}

lack of administration of antibiotics ${ }^{13}$ lack of unit policies, ${ }^{32}$ and nurse-patient ratio. ${ }^{16}$

Regarding the items which were coded as negative statements, although it is considered as high and moderate interventions; except that participants reported a low level of knowledge, which indicated that comprehensive training is needed under supervision in-service education units. In the current study, around half of the nurses thought benzodiazepines should be always preferred to manage agitation, although the recommended is other agents. ${ }^{33}$ In this study, findings were consistent with study ${ }^{34}$ nurse's beliefs that changing of ventilator circuit should be regular, while the change is only recommended if there is clear soiling or malfunctioning. In early exercise and mobilization, nearly half of nurses reported it to contribute to increasing the possibility of $\checkmark A P$, whilst the early exercise reduces prolonged hospitalization. ${ }^{34}$ In this study, findings are comparable with other studies in which nurses contrary believed the closed/in-line endotracheal suctioning is recommended, whilst the recommended is closed-suction system. ${ }^{30,31,34}$ Majority of nurses reveals that kinetic beds and prone positioning may reduce the risk of VAP, while both of them generally are not recommended. ${ }^{3}$ This reveals that closed-suction system and ventilator circuit were changed continually during daily practice, which is congruous with another study. ${ }^{24}$ That may be attributed to nonupdate VAP guidelines and absence or few qualified ICU nurses with a specific degree of VAP prevention, another reason it may be associated with VAP education resource, more than one third of our participants said that they had received an external course and less frequently in in-service training and nursing school, that corroborate with studies conducted among Jordanian ICU nurses that found a majority of nurses gained their knowledge not directly from nursing schools and in in-service training.15,16

Concerning the barriers of the nurses on adherence to VAP prevention guidelines, most of them selected the option of "sometimes" in this respect. The items that attracted the answers in the option of "sometimes" were regarding lack of equipment such as gloves and face masks, forgetting to practice the sterile technique and lack of time, which was congruous with regional study among Jordanian critical care nurses, also indicate the limited of infection control equipment's is unsafe practice in Jordan hospitals and forms a significant challenge. ${ }^{18}$ On the other hand, the items of "Shortage of staff in the ICU," "lack of VAP knowledge," and "lack of educational programs" attracted the majority of the answers in the option of "always." These results were in agreement with several studies; in one study, the author indicates the small number of staff in the ICU, and it constitutes the main barrier. ${ }^{35}$ Another Jordanian critical care nurse who works with equal nurses: patient ratio reflects better VAP compliance than others. ${ }^{16}$ However, the adequate number of nurses in ICUs may reduce the VAP rate and ICU length stay. Lack of VAP knowledge, and educational programs presented main barriers among Jordanian critical care nurses. ${ }^{15,17}$ Sufficient nurses' knowledge contribute to provide perfect patient care, create a trust to apply optimal decisions and enhance ventilated patients outcomes. ${ }^{24}$

In the current study, we observed the expert's nurses and the master degree revealed an adequate knowledge, when nurses' degree level and experience increased, their level and experience of knowledge as well increased, which is congruence with studies. ${ }^{26,31}$ Availability of an expert ICU qualification contributes a significantly better for VAP prevention.

On the other hand, nurses who received previous VAP education showed adequate knowledge than their colleagues who did not receive, these findings were supported by studies that revealed that continuous education and training enhanced both knowledge and compliance related to VAP preventive measures and significant practical improvement were seen after education sessions. ${ }^{24}$ Continuing education programs are necessary to improve nurses' knowledge of VAP prevention, and nursing administrators and hospitals should be utilizing a systemic strategic and educational plan of VAP prevention.

There were some limitations. First, no sample selection method was used. Second, we have been unable to find out the impact of work climate of VAP knowledge prevention among critical care nurses; third, the study was conducted only at two hospitals and it can be difficult to generalize and apply it to other nursing populations.

In conclusion, the basic knowledge of VAP among nurses was adequate level. The study findings reflect that nurses gained this knowledge from daily routine and their schools, which is considered fundamental nursing skills. However, participants needed education on VAP to improve nursing skills and enhance patient's outcomes.

Policymakers and hospitals administrators should pay attention to implement and update VAP prevention guidelines, which would be useful for improving the quality of nursing care and increasing awareness of the nurses to make the right decisions. In additional, deans of nursing faculties should revise the undergraduate nursing curriculum in Jordan and incorporate acute care initiatives.

The results yielded showed main barriers nurses mentioned, these barriers may inhibit both the development and motivation of the personnel and increase the incidence of VAP 
complications, both national and institutional regulations are necessary to prevent barriers of VAP prevention.

Ethics Committee Approval: Ethical committee approval was received from the Near East University Institutional Reviews Board (IRB) (Reference number: 2017\47-420).

Informed Consent: Written informed consent was obtained from all participants who participated in this study.

Peer-review: Externally peer-reviewed. Written informed consent was sought from all participants.

Author Contributions: Conception M.N.A.; Design - M.N.A., K.A.A.; Supervision N.B.; Materials - M.N.A.; Data Collection and/or Processing - M.N.A.; Analysis and/or Interpretation - K.A.A.; Literature Review - K.A.A.; Writing - M.N.A.; Critical Reviews - N.B.

Acknowledgment: The authors would like to express gratitude to all participants and special thanks to King Abdullah University Hospital and Islamic Hospital for allowing data collection.

Conflict of Interest: The authors have no conflicts of interest to declare.

Financial Disclosure: The authors declared that this study has received no financial support.

\section{REFERENCES}

I. Torres A, Niederman MS, Chastre J, et al. International ERS/ ESICM/ESCMID/ALAT guidelines for the management of hospital-acquired pneumonia and ventilator-associated pneumonia: Guidelines for the management of hospital-acquired pneumonia (HAP)/ventilator-associated pneumonia (VAP) of the European respiratory society (ERS), European society of intensive care medicine (ESICM), European society of clinical microbiology and infectious diseases (ESCMID) and Asociación Latinoamericana del Tórax (ALAT). Eur Respir J. 2017;50:1700582. [CrossRef]

2. Ali NS. Critical care nurses' knowledge and compliance with ventilator-associated pneumonia bundle at Cairo university hospitals. J Nurs Educ Pract. 2013;4:66-77.

3. Klompas M, Branson R, Eichenwald EC, et al. Strategies to prevent ventilator-associated pneumonia in acute care hospitals: 2014 update. Infect Control Hosp Epidemiol. 2014;35:I33-154.

4. Micik S, Besic N, Johnson N, Han M, Hamlyn S, Ball H. Reducing risk for ventilator associated pneumonia through nursing sensitive interventions. Crit Care Nurse. 2013;29:261-265. [CrossRef]

5. Larsson J, Itenov TS, Bestle MH. Risk prediction models for mortality in patients with ventilator-associated pneumonia: A systematic review and meta-analysis. J Crit Care. 2017;37:II2-II8. [CrossRef]

6. Balkhy H, El-Saed A, Maghraby R, et al. Drug-resistant ventilator associated pneumonia in a tertiary care hospital in Saudi Arabia. Ann Thorac Med. 2014;9:104-III. [CrossRef]

7. Roquilly A, Feuillet F, Seguin P, Lasocki S, Cinotti R, Launey Y. Empiric antimicrobial therapy for ventilator-associated pneumonia after brain injury. Eur Respir J. 2016;47:1219-1228. [CrossRef]

8. Craven DE, Lei Y, Ruthazer R, Sarwar A, Hudcova J. Incidence and outcomes of ventilator-associated tracheobronchitis and pneumonia. Am J Med. 2013;126:542-549. [CrossRef]

9. Ashu S, Atul P, Paramdeep K, Rajesh I. Incidence and attributable costs of ventilator-associated pneumonia (VAP) in a tertiary-level intensive care unit (ICU) in Northern India. J Infect Public Health. 2015;8:127-135.

10. Yepez E, Bovera $M$, Rosenthal $V$, et al. Device associated infection rates, mortality, length of stay and bacterial resistance in intensive care units in Ecuador: International nosocomial infection control consortium's findings. World J Biol Chem. 2017;8:95-I0I. [CrossRef]

II. Afhami S, Hadadi A, Khorami E, Seifi A, Bazaz NE. Ventilatorassociated pneumonia in a teaching hospital in Tehran and use of the Iranian nosocomial infections surveillance software. East Mediterr Health J. 2013;19:883-887. [CrossRef]

12. Howaydah AO, Neven MG, Alaa ME, Tarek AF. Ventilator associated pneumonia, incidence and risk factors in emergency intensive care unit Zagazig University Hospitals. Egypt J Chest Dis Tuberc. 2017;66:703-708.

13. Samrah S. Impact of colistin-initiation delay on mortality of ventilator-associated pneumonia caused by A. baumannii. J Infect Dev Ctries. 2016;10:1129-II34. [CrossRef]

14. Aloush SM. Does educating nurses with ventilator-associated pneumonia prevention guidelines improve their compliance? Am J Infect Control. 2017;45:969-973. [CrossRef]

15. Hassan Z, Wahsheh M. Knowledge level of nurses in Jordan on ventilator-associated pneumonia and preventive measures. Nurs Crit Care. 2017;22:125-132. [CrossRef]

16. Sami A. Nurses' implementation of ventilator-associated pneumonia prevention guidelines: An observational study in Jordan. Crit Care Nurse. 2017;23:147-151.

17. Aloush S, Abdelkader F, Al-Sayaghi K, et al. Compliance of nurses and hospitals with ventilator-associated pneumonia prevention guidelines: A Middle Eastern survey. J Nurs Care Qual. 2018;33:814.

18. Al-Rawajfah OM. Infection control practices among intensive care unit registered nurses: A Jordanian national study. Nurs Crit Care. 2016;2l:E20-E27. [CrossRef]

19. Schreiber MP, Shorr AF. Challenges and opportunities in the treatment of ventilator-associated pneumonia. Expert Rev Anti Infect Ther. 2017;15:23-32. [CrossRef]

20. Lord R, Mayhew C, Korupolu R, et al. ICU early physical rehabilitation programs: Financial modeling of cost savings. Crit Care Med. 20l3;41:717-724. [CrossRef]

21. Muhammad WD, Mohammad AS. Evidence-based guidelines for prevention of ventilator-associated pneumonia: Evaluation of intensive care unit nurses' adherence. Am J Infect Control. 2018;46:7|I-7|3.

22. Shitrit P, Meirson M, Mendelson G, Chowers M. Intervention to reduce ventilator-associated pneumonia in individuals on longterm ventilation by introducing a customized bundle. J Am Geriatr Soc. 2015;63:2089-2093. [CrossRef]

23. Azzab MM, El-Sokkary R, Tawfeek M, Gabriel MG. Prevention of ventilator associated pneumonia in an emergency intensive care unit: An intervention study. Egypt J Med Microbiol. 2017;26:83-94. [CrossRef]

24. Akın KE, Hakverdioğlu YG, Parlar KS, Uzelli D. Knowledge levels of intensive care nurses on prevention of ventilator-associated pneumonia. Nurs Crit Care. 2014;19:26-33. [CrossRef]

25. Janssona M, Tero A, Pekka Y, Hannu S, Helvi K. Critical care nurses' knowledge of, adherence to and barriers towards evidence-based guidelines for the prevention of ventilatorassociated pneumonia-A survey study. Intensive Crit Care Nurs. 2013;29:216-227. [CrossRef]

26. Hsin-Lan L, Chih CL, Li-Yu Y. Critical care nurses' knowledge of measures to prevent ventilator-associated pneumonia. Am J Infect Control. 2014;42:923-925.

27. Tahereh NG, Leila K, Omid M, Mohammad N. The comparison of the effect of the head of bed elevation to 30 and 45 degrees on the incidence of ventilator associated pneumonia and the risk for pressure ulcers: A controlled randomized clinical trial. Iran Red Crescent Med J. 2017;19:14224. 
28. Beatriz AB. Nursing actions to prevent mechanical ventilation pneumonia in the intensive care unit: Review. Rev Lat Am Enfermagem. 2017;6:59-64.

29. Mogyoródi B, Dunai E, Gál J, Iványi Z. Ventilator-associated pneumonia and the importance of education of ICU nurses on preventionPreliminary results. Interv Med App/ Sci. 2016;8:147-151. [CrossRef]

30. Yaseen R, Salameh T. Saudi critical care nurses' knowledge of and barriers toward adherence to prevention of ventilator associated pneumonia guidelines. Nurs Health Sci. 2015;4:65-69.

31. Al-Sayaghi KM. Prevention of ventilator-associated pneumonia: A knowledge survey among intensive care nurses in Yemen. Saudi Med J. 2014;35:269-276.

32. Al-Rawajfah $O$, Hweidi I, Alkhalaileh M, Khader $Y$, Alshboul S. Compliance of Jordanian registered nurses with infection control guidelines: A national population-based study. Am J Infect Control. 2013;41:1065-1068. [CrossRef]

33. Pérez-Granda MJ, Muñoz $P$, Heras $C$, et al. Prevention of ventilator-associated pneumonia: Can knowledge and clinical practice be simply assessed in a large institution? Respir Care. 2013;58:1213-1219. [CrossRef]

34. Balas MC, Vasilevskis EE, Olsen KM, et al. Effectiveness and safety of the awakening and breathing coordination, delirium monitoring/management, and early exercise/mobility bundle. Crit Care Med. 2014;42:1024-I036. [CrossRef]

35. Jordan A, Badovinac A, Spali S, et al. Factors influencing intensive care nurses' knowledge and attitudes regarding ventilatorassociated pneumonia and oral care practice in intubated patients in Croatia. Am J Infect Control. 2014;42:III5-III7. [CrossRef] 